\title{
IMPROVEMENT IN QCL ABSORPTION BASED CO TRACE GAS SENSOR SYSTEM
}

\author{
Suryakanta R. Patil ${ }^{1}$, Nadir Charniya ${ }^{2}$, Shivangi Chourasia ${ }^{3}$, Alok Verma ${ }^{4}$ \\ ${ }^{I}$ Department of Electronics and Telecommunication, VESIT, Mumbai Maharashtra, India \\ ${ }^{2}$ Department of Electronics and Telecommunication, VESIT, Mumbai Maharashtra, India \\ ${ }^{3}$ Photonics Division, SAMEER, IIT Campus, Powai, Mumbai Maharashtra, India \\ ${ }^{4}$ Photonics Division, SAMEER, IIT Campus, Powai, Mumbai Maharashtra, India
}

\begin{abstract}
This paper describe development of Trace gas sensor that can detect Carbon Monoxide (CO) gas by using a wavelength tuned Distributed feedback-Quantum Cascade LASER (DFB-QCL). Trace gas sensor design is based on principle of Direct Infrared Absorption Spectroscopy. High Resolution Transmission Molecular Spectroscopic (HITRAN) Analysis is carried out for selecting fundamental absorption line of CO R(12) near $2190.0175 \mathrm{~cm}^{-1}$ and the characteristics of wavelength tunable DFB-QCL has been analyzed, for detection of CO R(12) at same wavenumber. Fixed length gas cell of $10 \mathrm{~cm}$ is used to achieve highest sensitivity and improved detection limit. We are improving the response time and reducing the various noises present in the gas sensor using signal processing with the help of NI LabVIEW software and hardware. Also effect of chopper frequency variation, Mercury Cadmium Telluride (MCT) detector distance variation on Full Width Half Maxima (FWHM), Intensity of DFB-QCL is observed with and without gas sample present in fixed gas cell.
\end{abstract}

Keywords: CO gas, DFB-QCL, NI LabVIEW, NI USB 6351

\section{INTRODUCTION}

$\mathrm{CO}$ is considered to be one of the main global pollutants. Principal sources of $\mathrm{CO}$ production and emission to the atmosphere include various incomplete partial oxidations of carbon-containing compounds associated with automobiles combustion, fossil fuels burning by power plants, and petrochemical-related processes. Significant influence of $\mathrm{CO}$ upon atmospheric chemistry was recognized due to its close relation to the degradation of the ozonosphere and creation of acid rain, resulting from its reaction with hydroxyl $(\mathrm{OH})$ and its indirect effect on the accumulation of greenhouse gases. Even at low concentration levels $\mathrm{CO}$ may cause serious threat to human life since it is colorless, odorless and tasteless, and therefore hard to sense. Accurate and reliable real time monitoring of $\mathrm{CO}$ accumulation is important in medical diagnostics, since $\mathrm{CO}$ concentration levels of sub ppm can affect the human respiratory system [1]. Tang Yuanyuan, et al. [2] have developed a set of instrument for direct measurements of $\mathrm{CO}$ trace gases at $\sim 2190 \mathrm{~cm}^{-1}$ (or $\sim 4.57 \mu \mathrm{m}$ ) based on room-temperature pulsed QC lasers has been introduced. The instrument combines two room-temperature pulsed QC lasers with a long-path multi-pass absorption cell to achieve the detection requirements of high sensitivity, selectivity and rapid response. This system is capable of taking highly sensitive measurements with a time resolution of 1 second, allowing time-resolved investigations of individual plumes and sources. Such instrument has been employed to monitor CO emissions in Shanghai during the EXPO 2010. The data is also analyzed to examine the hypothesis that road vehicle traffic is the common source of $\mathrm{CO}$ and $\mathrm{NO}$ emissions in this local region. Accuracy and detection limits of the chemical gases are possible due to fundamental vibrational bands in the mid-infrared ( 3 to $24 \mu \mathrm{m}$ regions) and selective detection due to absorption of light by rotational-vibrational transition of these bands.

The large wavelength coverage of quantum cascaded LASER provides mid-infrared LASER absorption spectroscopy with ultra-high resolution and sensitivity. The high quantum cascaded LASER power allows use of advanced detection techniques improving sensing limits and decreasing complexity and size of trace gas sensor. The detection limit of Infrared Absorption based gas sensor is limited due to various noise sources, such as, flicker noise, detector noise, acquisition non-linearity.

Our prime objective is to detect $\mathrm{CO}$ for medical and environmental applications and observe the various effects on FWHM and Intensity of DFB-QCL laser. In order to target the optimal interference free CO R (12) absorption doublet at $\sim 2190 \mathrm{~cm}^{-1}$ EC-QCL has used.

\section{LINE SELECTION FOR CO NEAR $\sim 2190 \mathrm{~cm}^{-1}$}

\section{$(\sim 4.57 \mu \mathrm{m})$}

Detection of CO in the MWIR around $2190 \mathrm{~cm}^{-1}$ allows high sensitivity measurement, not possible with near-IR CO sensors, and the potential for measurements with significantly shorter absorption path lengths. The transitions in the $\mathrm{CO}$ fundamental band are extremely well characterized in terms of spectroscopic parameters such as line position, line strength, and line broadening parameters. These features allow both the identification and 
quantification of the molecular species, such as atmospheric trace gases. Molecules may undergo transition between electronic, vibrational, and rotational states when exposed to electromagnetic radiation, resulting in absorption spectra. The fundamental ro-vibrational bands are present near 2190 $\mathrm{cm}^{-1}$ [2]. The Fig-1 shows the simulated spectra for $\mathrm{CO}$ at $\mathrm{P}$ $=1 \mathrm{~atm}, \mathrm{~T}=300 \mathrm{~K}$ using HITRAN (2008) database [3].

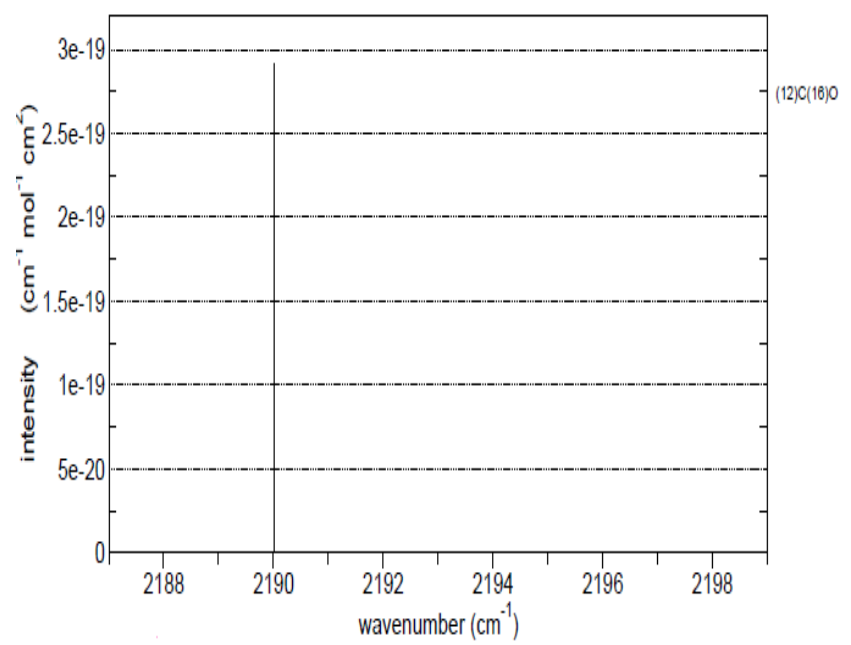

Fig-1: Simulated spectra for $\mathrm{CO}$ at $\mathrm{P}=1 \mathrm{~atm}, \mathrm{~T}=300 \mathrm{~K}$ using HITRAN (2008) database [2]

\section{LASER ABSOPTION SPECTROSCOPY}

LAS (LASER Absorption Spectroscopy) of target gas species, which is based on the Beer-Lambert absorption law, effectively determines real-time gas Concentrations. Beer Lambert law given by equation (1) [4],

$$
I(v)=I_{0} \cdot e^{-\alpha(v) \cdot L}
$$

Where ' $I$ ' is the intensity of light passing through the absorbing medium, ' $I_{0}$ ' is the input intensity, ' $L$ ' is the optical path length, ' $v$ ' is the radiation frequency, and ' $\alpha(v)$ ' is the absorption coefficient of a specific target species. The product ' $\alpha(v) . L$ ' represents the spectral absorbance ' $A(v)$ ' given by equation (2),

$$
A(v)=\alpha(v) \cdot L
$$

The spectral absorption coefficient for a single rotationalvibrational transition of some specified gas ' $g$ ' can be written as,

$$
\alpha(v)=P \chi_{i} S_{i}(T) \Phi_{i}(v)
$$

Where $P[\mathrm{~atm}]$ is the pressure of the medium, $S_{i}(T)\left[\mathrm{cm}^{-2}\right.$ $\left.\mathrm{atm}^{-1}\right]$ is the line strength, $\Phi_{i}(v)\left[\mathrm{cm}^{-1}\right]$ is the lineshape function, ' $\chi_{i}$ ' is the mole fraction of the absorbing species, and the $L[\mathrm{~cm}]$ is the path length through which the radiation passes. Hence the spectral peak absorbance for a single rotational-vibrational transition of gas can be written as:

$$
A(v)_{\text {peak }}=P \chi_{i} S_{i}(T) L \Phi_{i}(v)_{\text {peak }}
$$

Where $\Phi_{i}(v)_{\text {peak }}$ is the peak value of the lineshape function. There are three type of lineshape function Gaussian lineshape function, Lorentzian lineshape function, Voigt lineshape function. Table-1 shows peak absorbance coefficient for $\mathrm{CO}$ transitions.

Table-1: Peak absorbance Coefficient for $\mathrm{CO}$ transition

\begin{tabular}{|l|l|}
\hline Gas Transition & $\mathrm{CO} \mathrm{R}(12)$ \\
\hline Linecenter frequency $\mathrm{V}_{0}\left(\mathrm{~cm}^{-1}\right)$ & 2190.017 \\
\hline $\begin{array}{l}\text { Line strength } \mathrm{S}\left(\mathrm{cm}^{-2} \mathrm{~atm}^{-1}\right) \\
\text { HITRAN }(2008)\end{array}$ & 7.131 \\
\hline $\begin{array}{l}\text { Peak height of lineshape function }(\mathrm{cm}) \\
\phi_{v}\left(v_{0}\right)\end{array}$ & 0.5897 \\
\hline Absorption $\mathrm{I}=\mathrm{I}_{0} \times \mathrm{e}^{-\alpha(\mathrm{v}) \mathrm{L}}$ & $\mathrm{I}=\mathrm{I}_{0} \times 0.71$ \\
\hline
\end{tabular}

\section{EXPERIMENTAL SETUP}

For detection of CO gas wavenumber $2190 \mathrm{~cm}^{-1}$ is selected, where R (12) transition of CO gas is present and it is strongly interference free from other gas species. A distributed feedback QCL operating near $2190 \mathrm{~cm}^{-1}$ wavenumber (L12004-2190 H-C, HAMMATSU) is employed as the light source [5] which is capable of providing a tuning from $2192.18 \mathrm{~cm}^{-1}-2188.57 \mathrm{~cm}^{-1}$. DFBQCL [5] is tuned to $2190 \mathrm{~cm}^{-1}$. Wavenumber so that CO gas can be probe at ppm level. The QCL is mounted in ILX light wave LASER housing. A TEC (thermo electrically cooled) temperature controller (Wavelength Electronics LFI-3751) [6] is used to tune DFB-QCL LASER at desire wavelength by controlling the DFB-QCL LASER chip temperature. The QCL is driven by a high compliance LASER diode current source (ILX LDX-3232) of $15 \mathrm{~V}$ and $4 \mathrm{~A}$ current [7]. The transmitted output was coupled to the spectrum analyzer

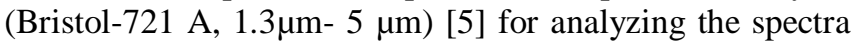
near the desired wavelength as shown in Fig-2.

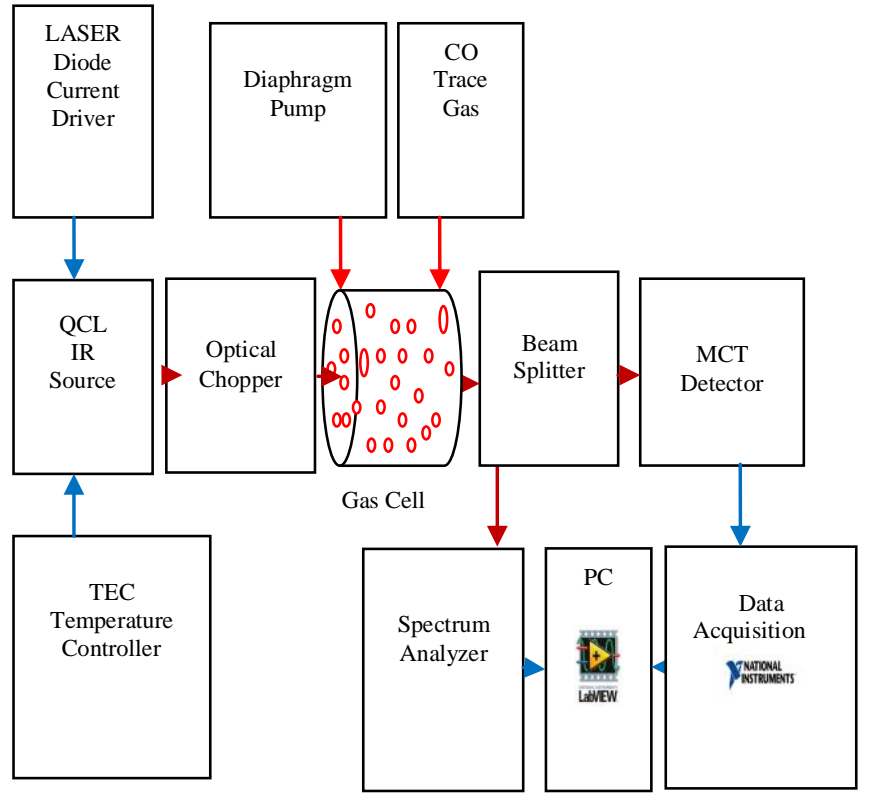

Fig-2: Block diagram for detection of $\mathrm{CO}$ gas 
A fixed length gas cell of $10 \mathrm{~cm} \mathrm{[8]} \mathrm{is} \mathrm{connected} \mathrm{to} \mathrm{CO}$ gas cylinder and diaphragm pump for analyzing results of detection of $\mathrm{CO}$ gas at different concentration. As light passes through a gas cell, fragments of the light energy will be absorbed by the gas molecules resulting in distinctive absorption bands in the absorption spectrum which enables recognition of the chemical species. The output of the QCL is modulated by an optical chopper (Thorlabs MC 2000) [9] with a chopping frequency of $100 \mathrm{~Hz}$ and coupled to a 10 $\mathrm{cm}$ single pass gas cell. The transmitted output was splitted by a 50-50 beam splitter, one part was coupled to the Laser spectrum analyser (Bristol-721 A) for analyzing the spectra near the desired wavelength and the other part was coupled to MCT detector with a built-in preamplifier (PVI-4TE-5 Vigo System) [10]. MCT detector signal is acquire by using NI USB 651 Card [11] and LabVIEW software [12] to observe changes.

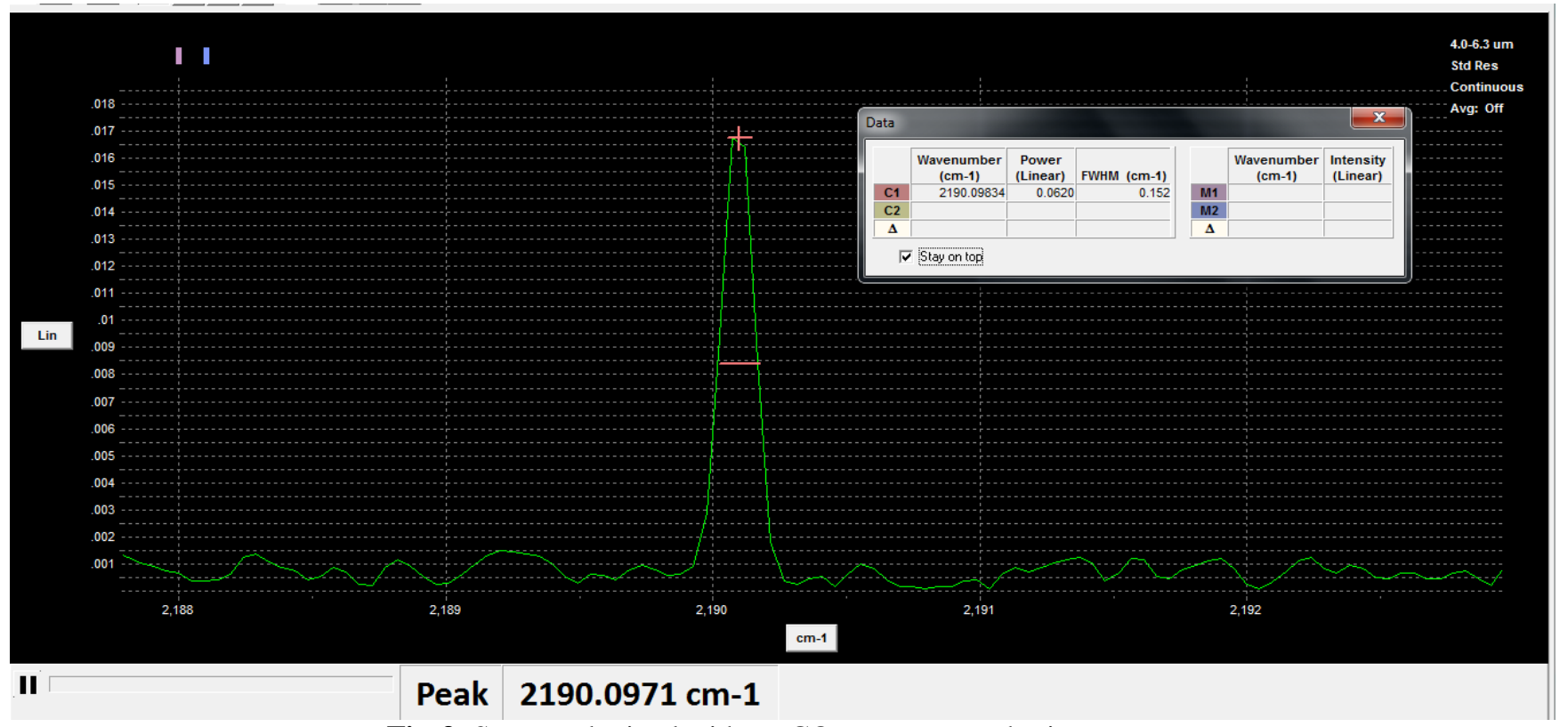

Fig-3: Spectra obtained without $\mathrm{CO}$ gas at atmospheric pressure

A certified 10 ppmv $\mathrm{CO}$ in $\mathrm{N}_{2}$ mixture was used to obtain known concentrations of the investigated gas using MFC [13]. Fig-3 and Fig-4 shows the spectra of $\mathrm{CO}$ at $2190 \mathrm{~cm}^{-1}$ before and after inserting the gas in the gas cell. It is found that there is a decrement of 0.04 in the optical power (linear) when 10ppm CO in $\mathrm{N}_{2}$ was filled in the gas cell.

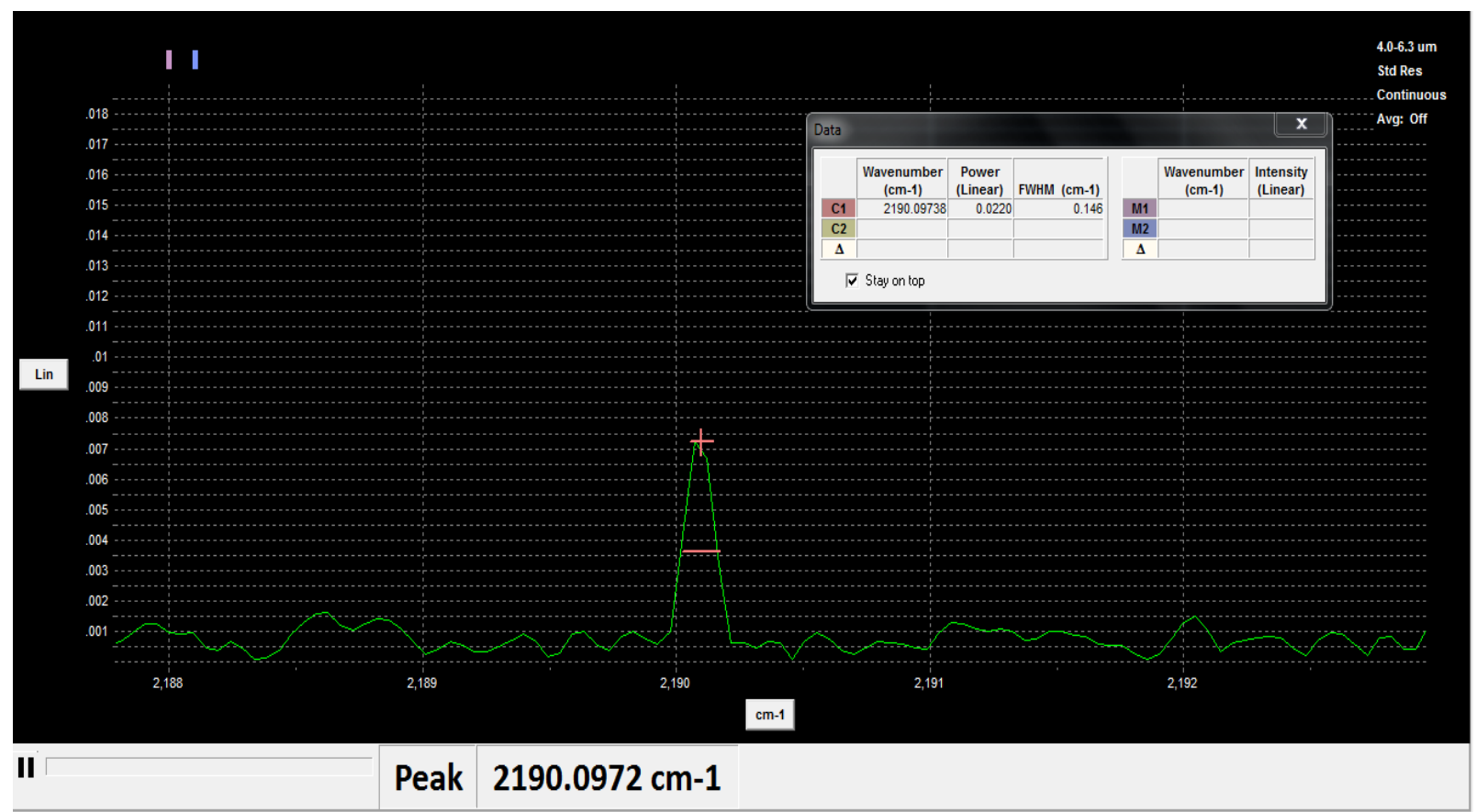

Fig-4: Spectra obtained with 10 ppmv $\mathrm{CO}$ in $\mathrm{N}_{2}$ at atmospheric pressure 
Fig-5 shows the MCT data acquired using DAQ without CO gas in gas cell with $42 \mathrm{mV}$ amplitude. Now gas cell is filled with $10 \mathrm{ppm} \mathrm{CO}$ in $\mathrm{N}_{2}$. It is found that amplitude of MCT detector signal has reduced to $32 \mathrm{mV}$ giving results for $\mathrm{CO}$ gas absorption inside gas cell as shown in Fig-6.

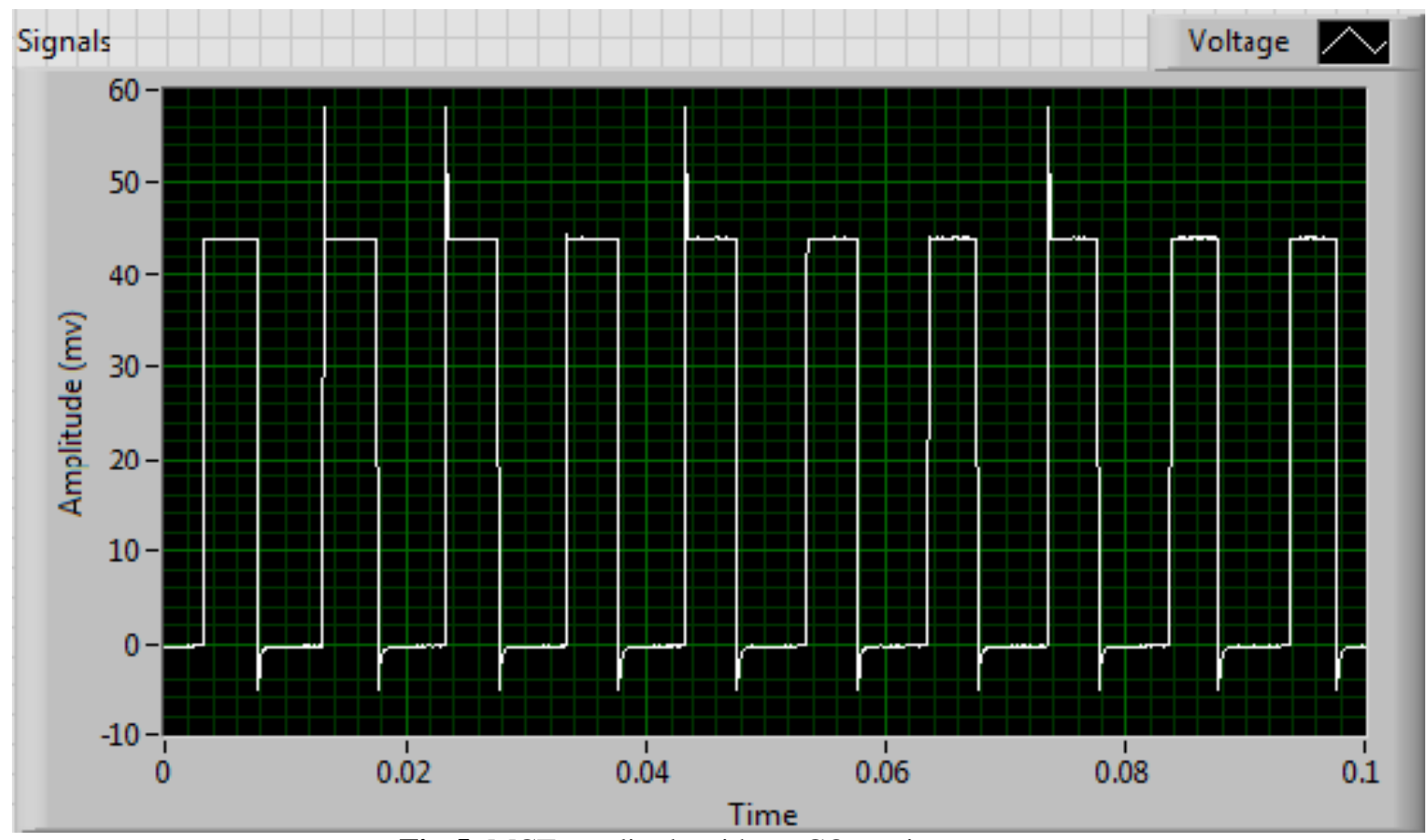

Fig-5: MCT amplitude without CO gas in vacuum

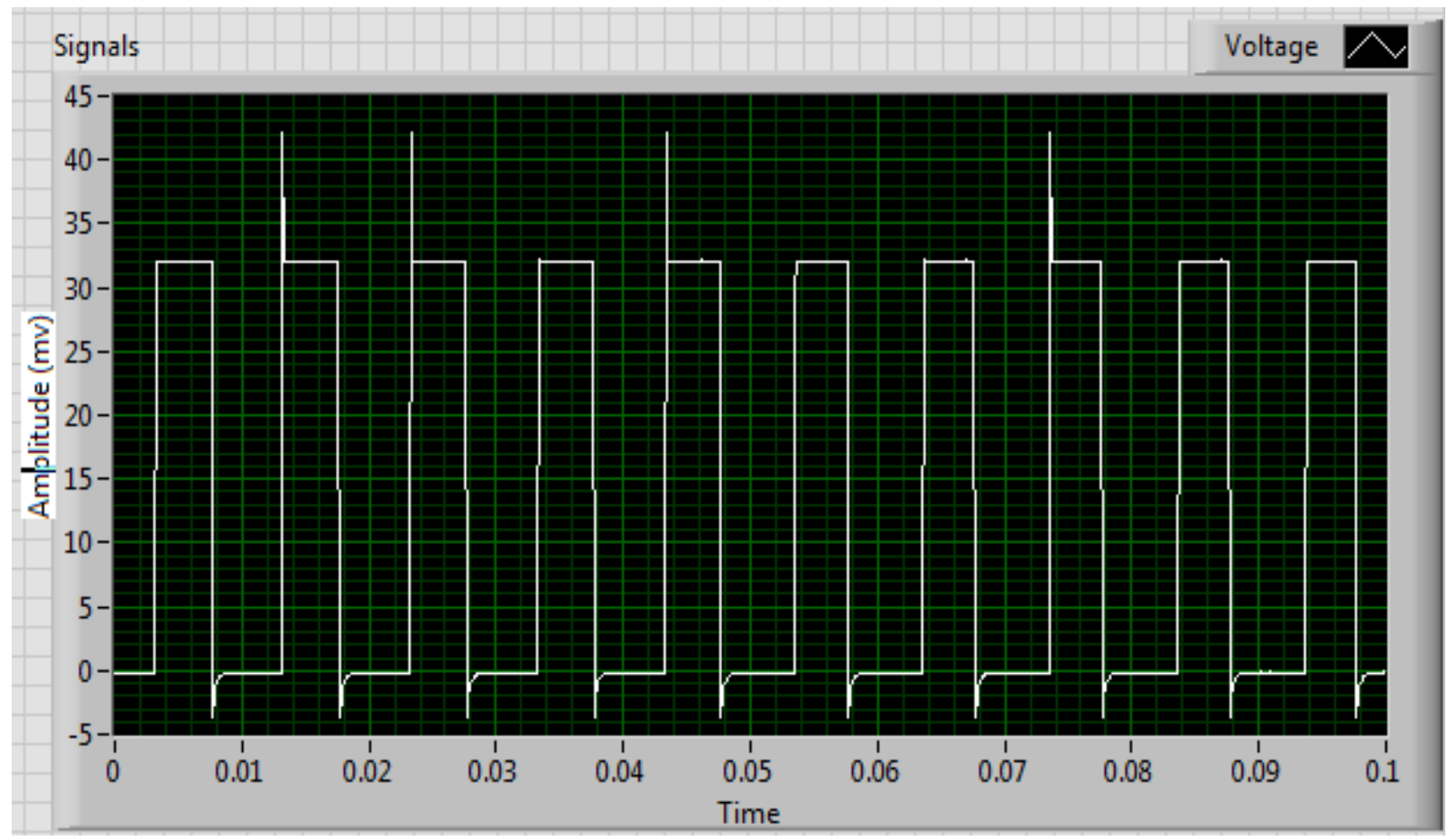

Fig-6: $\mathrm{MCT}$ amplitude with $10 \mathrm{ppmv} \mathrm{CO}$ in $\mathrm{N}_{2}$ gas at atmospheric pressure

\section{RESULT OF CO GAS DETECTION}

Table-2 shows the Practical Gas detection values for 9 ppm concentration of $\mathrm{CO}$ gas with $10 \mathrm{~cm}$ fixed length gas cell and $1 \mathrm{~atm}$ pressure at $\mathrm{T}=293 \mathrm{~K}$ near $2190.0175 \mathrm{~cm}^{-1}$. Absorption coefficient $\alpha(v)$ has been calculated using different lineshape function. Gas detection results are analyzed with respect of initial voltage levels when there is no gas inside the gas cell. As known concentration of gas is filled in fixed length gas cell, due to interaction of DFBQCL Laser beam with gas inside the fixed length gas cell some of intensity is reduced which depicts the gas detection. 
Table-2: Practical and theoretical absorption of CO gas near $2190.0175 \mathrm{~cm}^{-1}$

\begin{tabular}{|l|l|l|}
\hline Gas Transition CO R(12) & Theoretical & Practical \\
\hline $\begin{array}{l}\text { Linecenter frequency } \\
V_{0}\left(\mathrm{~cm}^{-1}\right)\end{array}$ & 2190.017 & 2190.097 \\
\hline $\begin{array}{l}\text { Absorption } \\
\mathrm{I}=\mathrm{I}_{0} \times \mathrm{e}^{-\alpha(\mathrm{v}) \mathrm{L}}\end{array}$ & 0.0313 & 0.032 \\
\hline
\end{tabular}

\section{EFFECT OF DISTANCE VARIATION ON INTENSITY AND FWHM OF DFB-QCL LASER \\ BEAM}

To observed effect on Intensity and FWHM of laser beam due to distance variation, output of the DFB-QCL is flash on spectrum analyzer through $10 \mathrm{~cm}$ fixed length gas cell. Table-3 summaries the effect of distance variation in between spectrum analyzer and DFB-QCL LASER source. Distance between spectrum analyzer and LASER source is varied in steps of $20 \mathrm{~cm}$ when $\mathrm{CO}$ gas is not present. It is observed that power decreases, as LASER beam is travelling longer distances but FWHM will remain constant as there is no absorption.

Table-3: Effect of Distance variation in between DFB-QCL Laser and Spectrum Analyzer

\begin{tabular}{|l|l|l|l|l|}
\hline $\begin{array}{l}\text { Sr. } \\
\text { No }\end{array}$ & $\begin{array}{l}\text { Distance } \\
(\mathrm{cm})\end{array}$ & $\begin{array}{l}\text { Wavenumber } \\
\left(\mathrm{cm}^{-1}\right)\end{array}$ & $\begin{array}{l}\text { Normalize } \\
\text { Power }\end{array}$ & $\begin{array}{l}\text { FWHM } \\
\left(\mathrm{cm}^{-1}\right)\end{array}$ \\
\hline 1 & 20 & 2190.7315 & 0.0510 & 0.145 \\
\hline 2 & 40 & 2190.7481 & 0.0310 & 0.145 \\
\hline
\end{tabular}

\section{CONCLUSION}

HITRAN 2008 analysis of CO gas is performed for selecting strong absorption line free from other interfering gas species. For CO detection wavenumber $2190 \mathrm{~cm}^{-1}$ is selected where $\mathrm{R}(12)$ ro-vibrational peak is present. The $\mathrm{CO}$ sensor system has $1 \mathrm{sec}$ response time operating near $2190 \mathrm{~cm}^{-1}$ and 10 ppmv concentration at the atmospheric pressure was detected. When no gas is present in gas cell and the path length is increased, then there is only decrease in power but FWHM of DFB-QCL Laser beam is remain unaffected.

\section{ACKNOWLEDGMENTS}

I would like to express our heartfelt thanks to Principal VESIT, Mumbai, Director - SAMEER (R\&D Govt. of India) for extending all the facilities required for carrying out project work. I would like to thanks N. Sreevalsen, Poonam Lamture and all concerned individuals those who have directly or indirectly extended their valuable support and contribution for this work.

\section{REFERENCES}

[1]. P. Stefanski1 and R. Lewicki, "Sensitive Detection of CO using a Compact High Power CW DFB-QCL based QEPAS Sensor", Optical Society of America (OSA), pp. 12, 2013
[2]. Kan Ruifeng, Liu Jianguo, He Yabai, Zhang Yujun, Xu Zhenyu, Ruan Jun and Geng Hui, "Measurements of NO and $\mathrm{CO}$ in Shanghai urban atmosphere by using quantum cascade lasers", Vol. 19, No. 21, OPTICS EXPRESS, OSA, pp. 224-232, 10 October 2011.

[3]. "Spectral Analysis", available at: www.cfa. harvard. edu/hitran/, (Accessed: 2013).

[4]. Shivangi Chaurasia, Niyati Chetwal, Indrajit Bairagi, Alok. J. Verma, "QCL based direct absorption for finding the detection limit of CO trace gas sensor", Fourth International Conference on Perspectives in Vibrational Spectroscopy, May, 2013

[5]. "CO LASER", available at: "http://www.hamamatsu .com/us/en/product/category/1001/1006/L1200 4-2190 HC/index.html", (Accessed: 2014).

[6]. "TEC CONTROLEER LFI 3751", available at: "http:// www.teamwavelength.com/downloads/Datasheets/lfi3751m an.pdf", (Accessed:2014)

[7]. "Laser Driver Current Source ILXLDX3232", available at:"http:/www.boselec.com/products/Documents/ILXLDX3 232powersup", (Accessed: 2013).

[8]. Storm Series 10 cm Gas Cell" http://www.specac.com/Products/gas-transmissioncell/short-pathlength-gas-cell/633" (Accessed: 2014) [9]. "Optical Chopper MC1F10", available at: "http://www.thorlabs.com/thorproduct.cfm?partnumber= MC1F10", (Accessed: 2013).

[10]. "MCT (PVI-4TE-5)" available at: "http://boselec.com/product/VigocatalogWWW4-2310.pdf.pdf.pdf', (Accessed: 2013).

[11]. LabVIEW Function and VI Reference Manual, National Instruments available at: www.ni.com/Pdf/manuals321526b.pdf, (Accessed: 2013). [12]. "LABVIEW Software" available at: "www.india.ni.com", (Accessed: 2013).

[13]. "Mass Flow Controller" available at: "www.alicat.com/products/mass-flow-meters-and controller/mass-flow-controllers", (Accessed: 2013).

\section{BIOGRAPHIES}

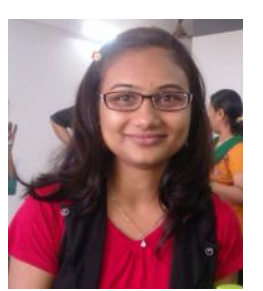

Suryakanta R. Patil was born on 26 February 1988. She received the Bachelor of Engineering degree in Electronics and Telecommunication from D. N. Patel College of Engineering, Shahada, India, in 2009. Currently, she is pursuing the Master of Engineering degree in Electronics and Telecommunication from Vivekanand Education Society's Institute of Technology, Mumbai, India. She is doing project from SAMEER an R\&D institute, Govt of India, Mumbai. She has 3 years of teaching experience and her interests of area are signal processing and optics. 


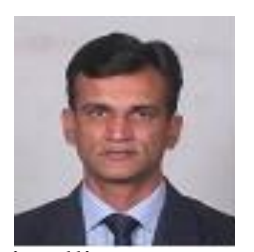

Nadir N. Charniya was born on September 30, 1966. He received the Master of Engineering degree in electronics from Victoria Jubilee Technical Institute, Mumbai, India, in 1995 and the Ph.D. degree in design of intelligent sensors using a neural network approach from Sant Gadge Baba Amravati University, Amravati, India, in 2010. He has about 24 years of teaching experience. He is currently working as a Professor, Department of Electronics and Telecommunications Engineering, VES Institute of Technology, Chembur, Mumbai, India. He has papers published in refereed international journals and international conference proceedings. He has chaired various conferences and delivered expert talk on signal processing techniques and their applications at various engineering colleges. His areas of interest include intelligent sensors and systems, neuro-computing techniques, signal processing, and their applications. Dr. Charniya is a member of the Institute of Electronics and Telecommunication Engineers, the Indian Society for Technology in Education, India, International Association of Computer Science and Information Technology. He is recipient of various research and laboratory development grants from AICTE, New Delhi and Universities. He has been invited to work as a reviewer for papers submitted to the IEEE transactions and Elsevier international journals in relation to his field of interest. A project on robotics guided by him received the First Prize and the "Maharashtra State Engineering Design Award" from the ISTE, India. His Ph.D. work on intelligent sensors received the First Prize under Post P.G. category in the Maharashtra State Interuniversity Research Project Exhibition "AVISHKAR-2008".

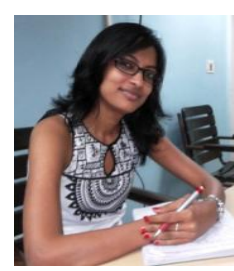

Shivangi Chaurasiya was born on $7^{\text {th }}$ September 1988. She received the Bachelor of Engineering degree in Electronics and Telecommunication from Rajiv Gandhi Proudyogiki Vishwavidyalaya, Bhopal, India, in 2010 with first position in Branch. She received Master of Technology degree in optoelectronics from Shri Govindram Seksariya Institute of Technology and Science, Indore (M.P), India in 2013 with first position in Branch. She has done specialization in optical communication. She joined SAMEER an R\&D institute, Govt of India in 2013 as Research Scientist. She is working in the field of gas sensors based on spectroscopy methods for various atmospheric monitoring applications.



Alok J. Verma received his Master' in Electronic Science from Dayalbagh Educational Institute, Agra, UP in 1989. He then taught in a state engineering college for two years. He was associated with IIT Delhi for his research work from 1992 and received his $\mathrm{PhD}$ degree on Optoelectronics in 1997. He joined SAMEER, an R\&D institute under Ministry of Communication \& IT, Govt of
India, in 1997 as Scientist. He has handled many projects in the areas of Development of Optical components and Photonics Packaging. His current research interests are Laser Spectroscopy for Space, Environmental monitoring, Homeland Security and Healthcare Health Care applications. He has over 50 research papers published in reputed Indian \& International Conferences and Journals. 